\title{
Building defects as a result of non-conceptual design
}

\author{
Jan Lojda ${ }^{1, *}$ \\ ${ }^{1}$ Faculty of Technology, The Institute of Technology and Business, Okružní 517/10, 37001 České \\ Budějovice, Czech Republic
}

\begin{abstract}
The contribution deals, describes and analyzes the fundamental connection between defects and the design of a building. Approximately half of the faults occur in building objects due to incorrect or faulty design activities. The non-conceptual approach to managing building preparation and insufficient and unqualified project design control poses problems with building use and increases the cost of maintenance. Improving engineering design and a comprehensive approach to project preparation and preparation is a way to increase the quality of design work. In his contribution, the author relies on quality management systems and their implementation in design offices and companies. At the same time, the term is a complex project, which would be a control tool for the quality of projection work.
\end{abstract}

\section{Causes of faults - misunderstanding of the life cycle of a building}

Each building work, edifice or a house pass through its life cycle from study to design, implementation, use and disposal. The life cycle can be defined as time period from idea creation to design, implementation of its use and or changes to the construction until its disposal. The emergence of each building is conditioned by inputs, both material and energy. Energy is consumed during the life of the building materials needed to operate and maintain the building. From the economic point of view, it is the period of use the most demanding construction in the life span.

Building objects, like any other big product, have individual lifetime. After the certain period of time all types of products, whether building or otherwise, are capable of performing their functions. During this time, they are able to perform their functions and their status allows their owner to benefit from the building's lye.

It is important to realize that the individual building elements and structures have a different lifespan. Thus, the building structures consist of long-lived and short-lived components. In the case of short life elements, we must expect that they will be the subject of not only maintenance but also renewal or reconstruction. This also influences the assessment of the impact of projects and implementation on the quality of the buildings. While short-life features can be remedied after a short time, long-life elements require both

\footnotetext{
*Corresponding author: lojda@mail.vstecb.cz
} 
high-quality project preparation and careful observance of the technology standards and regulations in their implementation.

Among the long-lasting features we include, for example basics, vertical bearing structures (chimneys can also be included in these structures), horizontal supporting structures, roof supporting structure, stair construction etc. As elements of short life we consider, for example surface finishing of walls (plasters, tiles, paints), floors, blending, filling of holes, insulation layers etc. We also include the technical equipment of the buildings and other equipment used for its function. It does not make sense to suggest, for example, systems that maintain thermal comfort in an object for a longer period than their period of moral life, i.e. obsolescence.

For completeness, let's take a look at how to define the life of buildings. For buildings, we generally recognize these types lifetime:

- Technical lifetime - the time we expect from the construction until its deterioration, and technical extinction provided normal maintenance. It usually exceeds the economic life.

- Economic lifetime - the time we expect from the construction until the moment of loss economic utility and meaningfulness, that is, the moment of permanent loss of income or loss usability by changing external conditions without the possibility of another use.

- Moral lifetime - the time we count from the start of the building to the moment the building is out of date - layout solutions, style, standards and technologies, market changes, development of the territory etc.

- Legal lifetime - time from approval to the moment of decision, authorization about the removal of the building.

The technical lifetime is mainly influenced by the construction system, maintenance, reconstruction and modernization. The lifetime of the constructions has a significant impact on the way in which the building was built, design of construction, construction system, technological implementation of elements of long-term life. Furthermore, the intensity of use, maintenance, reconstruction, modernization, overhaul, etc. The basic condition of long lifetime is regular maintenance.

The technical lifetime of the building influences the designers' skills and adherence to the technological regulations during construction. Typically, technological failures are considered to be the cause of construction failures during construction. However, on the basis of years of research, only half of building failures have caused half of the technological failure during construction and droughts, so the entire fifty percentage failures are due to poor designing. From the above it follows that at least half of the designer's quality and experience decides on the quality of the building work.

Buildings are designed with best intentions and in accordance with legislation. Great attention is paid to energy self-sufficiency, but less attention is paid to maintenance and recovery costs. Seemingly ecological constructions can bring a higher environmental burden than conventional buildings. It is therefore necessary to include in the discussions on building failures also the low-quality and non-conceptual work of the project teams. 
Examples of lifetime of structures and equipment:

Table 1. Examples of lifetime of structures and equipment (source: Decree.441 / 2013 Coll., § 21)

\begin{tabular}{|l|c|}
\hline \multicolumn{1}{|c|}{ Type of construction or equipment } & Estimated life in years \\
\hline Basics & $150-200$ \\
\hline Vertical constructions & $80-200$ \\
\hline Ceilings & $80-200$ \\
\hline Roof-covering & $40-80$ \\
\hline Plumbing constructions & $30-80$ \\
\hline Inner tiles-ceramic & $30-50$ \\
\hline Stairs & $80-200$ \\
\hline Door & $50-80$ \\
\hline Windows & $50-80$ \\
\hline Floor surfaces & $15-80$ \\
\hline Electrical installation & $25-50$ \\
\hline Lightning conductors & $30-50$ \\
\hline Heating & $20-50$ \\
\hline Indoor water pipe & $20-50$ \\
\hline Internal sewerage & $30-60$ \\
\hline Internal gas pipeline & $15-30-50$ \\
\hline Kitchen equipment & \\
\hline Housing cores & \\
\hline Elevators & \\
\hline
\end{tabular}

\section{Sources and category of faults}

The defect of the building is due to a faulty construction of some building structure. Bad execution may be due to the fault of the building designer, contractor, investor, or other participant in the construction. Blemish is always caused by human activity or vice versa inactivity. Completed buildings are defective during their use, maintenance and repairs, or as a result of building failure.

The failure of a building may result from a defect or from other causes. It may not, but may be, caused by a defective part of the building. The disturbances can cause shocks from 
surrounding traffic, as well as a defect in the base structure. Fault defects can be divided into defects and malfunctions, and defects and failures harmless (visual).

Hazardous defects and failures endanger healthy persons, safety, or stability construction or parts thereof. There is a risk of damage to health, or injury to economic damage in the next the use of the building, or the risk of collapsing some part of the building. In addition, it can at least invoke failure of the building or its part. Harmless defects and failures do not compromise the safety or health of persons, or the stability of the building, nor cause the building or its part to fail. However, it cancels the appearance of a building or visual. We can also break down defects and disturbances as obvious, visually detectable, which is can be detected during normal visual inspection and expert examination. There are also defects and malfunctions hidden, which cannot be detected in normal visual inspection and expert examination, because are hidden inside the structures.

The severity of the consequences of defects can be expressed using a scale. We call the severity of the defect (in terms of building use) by the term DS (Degree of severity) where 1 means a defect that does not have and will have no material or financial consequences, except for costs its removal and dissatisfaction with project participants. On the other hand, DS with a value of 5 anticipates defects that endanger the health and life of people. In general, any defect in the construction is removable. In some cases, the cost of removing the defect may be so high as to exceed an acceptable limit. The degree of removability is called DR (Degree of removability). Defects that can be removed quickly without high costs and labor effort have a DR equal to 1. On the other hand, non-removable defects will be DR equal to 5 . Depending on the value we achieve in DS and DR, the defects are divided into four categories $\mathrm{A}$ - D.

Table 2. Categorization of defects [1]

\begin{tabular}{|c|c|c|c|}
\hline Category & DS & DS x DR & Impacts \\
\hline A & 5 & 5 to 25 & Endangering life and health \\
\hline B & less than 5 & 10 to 20 & $\begin{array}{c}\text { The decline in the market value of the } \\
\text { construction relative to the expected amount, } \\
\text { unfavorable influence on the function of the } \\
\text { building (housing, production, transport, etc.) } \\
\text { threats to building activities }\end{array}$ \\
\hline C & less than 5 & 4 to 9 & $\begin{array}{c}\text { An unfavorable impression on building users, to } \\
\text { other people }\end{array}$ \\
\hline D & less than 5 & 1 to 3 & $\begin{array}{c}\text { Increasing the demand for maintenance of the } \\
\text { building and its systems }\end{array}$ \\
\hline
\end{tabular}

\subsection{Projection - inexperienced designer - project defects}

In construction practice, we often encounter an incorrect understanding of the concept of project defect. Because the project (i.e. project documentation) is firmly tied to the realization of the construction, only a defect is considered to be a defect in the project, resulting in a defect in the construction. Such a defect of construction can generally be defined as a disagreement in the actual execution of a particular building element with the correct execution. The origin of this disagreement lies either in a faulty proposal, i.e. in a project and in a faulty implementation, or only in a faulty implementation of a differently flawless design. 
The most common defects of the project, which as a result of the construction defect are:

- Inappropriate concept of a building solution based on insufficient exploration of the site or object to be reconstructed,

- Inappropriate detail design based on ignorance or inexperience of the designer,

- choosing an inappropriate product that does not meet the needs of its use in a particular building,

- an error in the calculation or use of an incorrect calculation method.

Defects of project documentation:

- It will not show up on the building.

- Causes a defect in the construction.

- It is captured by the building contractor - the construction company.

The percentage of defects from poorly processed project documentation is shown in the table (processed according to the anonymous development project approval). From these values, it is obvious that some constructions need to be dealt with more consistently even in the design phase.

Table 3. Percentage of defects from projects (anonymous resource)

\begin{tabular}{|c|l|c|}
\hline Position & \multicolumn{1}{|c|}{ Description } & Percentage share \\
\hline 1 & Rough construction & $6 \%$ \\
\hline 2 & Electrical installation & $5 \%$ \\
\hline 3 & Tiling, paving & $24 \%$ \\
\hline 4 & Sanitary engineering, installation & $7 \%$ \\
\hline 5 & Floors, floor coverings & $1 \%$ \\
\hline 6 & Internal plasters, interior finishes & $23 \%$ \\
\hline 7 & Surface treatment of metal structures & $3 \%$ \\
\hline 8 & Surface treatment - others & $9 \%$ \\
\hline 9 & Filling holes - doors & $10 \%$ \\
\hline 10 & Filling of holes - windows & $1 \%$ \\
\hline 11 & Air conditioning, heating and cooling & $\mathbf{1 0 0 \%}$ \\
\hline 12 & Others (everything else that can not be specified) & \\
\hline On the whole & & \\
\hline
\end{tabular}

\subsection{Construction production - non-observance of technological discipline}

Defects due to lack of technology have two sources of origin.

Supplier's fault:

- Technological failure - non-observance of the technological procedure, deadlines, regulations,

- Standards. 
- Failure to comply with the implementation project.

- Negligence.

Investor's guilt:

- The investor lets the construction project according to the project documentation processed for building control. At this stage, however, the project documentation is not for example, detailed. When executing them on site, the contractor often improvises. The result is unprofessional design and consequently occurring problems are encountered - e.g. in roof structures, in the waterproofing of the bottom structure (in particular, in waterproofing against pressurized water), etc.

- Due to savings, the investor lets a part of the building, its change, etc., be executed by the supplier without proper project processing. However, on the basis of this "savings", costs can be incurred much larger (often multiple) [2].

\subsection{Wear of building objects}

The fact that the construction is gradually degrading by aging and using it expresses the concept the wear of the building as a decrease in the quality and technical value of the property. By building we operate it, we help its wear in the influence of decisive influences. Reach structures for these influences are the degradation processes of functional parts, the consequence of which is gradual reducing the functional properties of the building as a whole depending on the intensity of the partial degradation processes. The wear and tear of buildings is understood as the state of construction works where the decline in quality and property prices is due to the use of atmospheric one influences and changes in the material. It expresses the specific technical state of the structure in the given moment. In order to find a real life, detailed analyzes are always necessary wear depending on the nature of the maintenance. The lifetime and wear of the building can be to be considered a continuous process. Wear is usually given in $\%$ of the value of the new building.

We distinguish between these types of wear and tear:

- physical - due to degradation processes, construction work, its component loses its quality in certain properties.

- moral - over time and the development of new materials, trends and other innovations there is a gradual obsolescence of the building work. The culmination of moral wear is modernization or other intervention that minimizes wear (general overhaul, reconstruction, etc.).

Estimation of building wear can be done by the following methods:

- linear method - the assumption is that the building is worn the same way all the time existence. It is an inaccurate and simple method. It is rather to find a rough one value estimation,

- nonlinear method - is based on the assumption that the structure does not absorb linearly. In the early years it grows slower and the age of depreciation is rising. Shows real wear more objectively,

- analytical method - is the most accurate but also the most practical. Based on an estimate the different lifetime of individual elements of the building with an emphasis on their long-term or long-short lifetime.

\subsection{Neglected maintenance}

Building failures caused by neglected maintenance can increase the cost of removing them. The most common mistakes of property owners include:

- Neglect of surface maintenance. 
- Insufficient attention paid to the penetration of water and moisture into structures.

- Exceeding technical life of technical equipment of buildings.

- Insufficient care for the construction during the winter.

- Delaying repairs and renovations.

Inappropriate use of a building work can cause a number of problems that cannot be treated during design and implementation. Inappropriate use of the construction work occurs:

- The building work will change the owner.

- The purpose of the building work in the locality has survived and its new application has to be sought.

- The planned lifetime of the construction work has been exceeded and the building is still being used.

- The user of the building has changed the use of the building by using other manufacturing technology and has caused its deterioration, for example, by aggressive chemicals.

- The user of the building neglects regular maintenance and repairs.

- The user of the building does not follow the security rules.

However, these faults and defects of the buildings do not result from the fault of the designer and cannot be attributed to the construction contractor. Their treatment in the preparation and construction of buildings is not possible and no statistics have been prepared to quantify the proportion of the defects thus generated. Although these defects can be quite common, they cannot be included in defects that can be pre-treated and avoided.

\section{Fault timing}

Probabilistic methods for verifying the reliability of structures involve only a small part of the actual causes of the failures. Therefore, the problem of determining the design (acceptable) probability of the failure (how safe is the safe construction?) Is still to be found. A significant part of the failures, in addition to mistakes in the activities of persons, are related to dangerous situations (impact, explosion, fire, extreme climatic conditions) that are not usually included in available theoretical models [3]. It turns out that risk engineering techniques that take into account a wider range of uncertainties than current probability procedures make it possible to contribute to further refine the current methods of verifying the reliability of structures [4]. The remarkable fact that the public is better prepared to tolerate certain risks than to tolerate the "probability of failure" [1] contributes to this. Therefore, it is legitimate to expect that probability methods of designing structures will be matched in the future with acceptable risk criteria.

\section{Impact of management tools application}

Regular maintenance and repairs prolong the physical usability of buildings in decades. It is the responsibility of the owner of the building or, more generally, the building to take care of it and keep it intact. It is not just a property need, but also a broader context, as well as the appearance of a building and its surroundings that affect the quality of public space. From the owner's point of view, not only the physical condition of the building, but also its usefulness is important. We can define usability as a satisfaction of the owner's idea how to use the building. The building work is always a capital that we can own and have the associated maintenance and operating costs (equity costs) or we can rent it, and the lease is then defined as the cost of foreign capital. In both cases, however, we need someone who 
will take care of the building or building and take care of its use in a changing environment. This activity deals with facility management and, in the wider sense of the word, Business Strategy, which defines the way the building is used. The changing environment of the building often leads to the need to redefine its purpose, and it is therefore necessary to mention a return strategy that is crucial to redefining the purpose of the building. Relationship quality (and therefore errors), project documentation, which in this article we deal lies in the fact that the designer should use these changes to count buildings and incorporate them into their design process of the project.

\subsection{Facility management}

The most common content of facility management (by Wikipedia):

- Operation, maintenance and servicing of technological equipment - providing operational maintenance of the building and technical equipment.

- Warranty and post-warranty service - Representing clients when dealing with third parties.

- Revisions, technical inspections - ensuring revisions according to valid ordinances and standards (eg electrics, lifts, appliances, etc.).

- Remote monitoring - connection of the object to the measuring and control system, distant trapping, fault messages, etc.

- Continuous emergency service - possibility of avoiding further damage to property, troubleshooting.

- OP and BOZP activities - inspection activities by fire engineer, PH and HP revisions.

- Key management - key economy records, general key system. Defects due to lack of technology have two sources of origin.

\subsection{Applying theory of recovery in building practice}

Applying the theory of return is addressed by a number of authors. The recovery strategy is a strategy chosen by the organization to restore critical operations and systems to their normal state and to resolve economic difficulties. This is the process where a business company resumes its business because of economic difficulties. It is a set of logical steps that gradually reduce operating costs and sell off unnecessary assets to the extent that a profit is created that invests in a whole new business. The progress of the amount of funds over time has a W-shape in graphical terms, as the company is found twice with zero funds. For the first time, business failure (in the case of buildings) and the second time in investing in a new business (building reconstruction). Rohstein [5] points to problems with the return strategy in his Disaster Recovery Testing: Exercising Your Contingency Plan.

\subsection{BIM and normative base, expert system}

Building Information Modeling (BIM) is a modern, intelligent process modeling and project management model. It facilitates the exchange of information in the process of designing, building and using the building. It enables building and managing land and civil engineering infrastructure projects - faster, more economical, and with less impact on the environment. Modern software tools help meet BIM processes and methodology. Autodesk's BIM software offers a broad portfolio of solutions for design, visualization, simulation and collaboration based on rich intelligent model information. This allows for better, more informed decision making and eliminates obstacles in the construction process. 
The main benefits of BIM are the possible increase in productivity of work, total saving in the construction and maintenance of the building, avoiding errors in the project as well as in construction and use, increasing control over the project and increasing its profitability. From the above mentioned advantages, the elimination of the errors resulting from the cooperation on the project and the improvement of the interconnection of activities during the construction, with a positive impact on the quality of the construction work, is significant from the point of view of this contribution.

The Building Information System allows for the extensive use of various types of downstream expert systems through programs to ensure mutual compatibility between the BIM and the expert system. Expert systems are computer programs that simulate the decision-making of an expert in solving complicated tasks and using appropriately coded, explicitly expressed knowledge taken from an expert in order to achieve decision-making at the design level of the construction work in the chosen problem area. The latest expert systems do not work with just one knowledge base, but they also use a larger number of independent knowledge bases - so-called knowledge sources. Each of these knowledge bases records its conclusions on a whiteboard, a shared data structure that is accessible to all knowledge sources [6]. The information on the whiteboard is important for the operation of the remaining resources. This activity is based on a realistic idea where a group of experts of various specialties solves a certain task in front of the board, to which they write a variety of knowledge about the problem solved. Each expert picks up data on the blackboard that matches his / her specialization, processes them and writes the results again on the board.

The use of expert systems together with BIM offers a whole new level of quality assurance of design work on building projects.

\subsection{Improving structural engineering design and quality management systems}

The quality of the construction preparation and its influence on the quality of the project documentation and the subsequent implementation and realization of the construction directly affect the final quality of the construction work. The ways in which the good preparation of the construction works in practice are as follows:

- The designer receives a back-up from the building technician at a time when a potential error can still be corrected

- The building technologist identifies and, if necessary, eliminates difficult-to-achieve parts of building structures or the entire construction.

- Building preparation is a multistage process that allows for the removal of errors as soon as they occur.

- It is easy to implement a quality management system to build a building and increase its reliability and efficiency.

One of the tools to achieve a quality building project is the introduction of a quality management system. The system must be functional, it must penetrate all the critical points (nodes) during the preparation and the construction itself. It must also ensure the proper conduct of tests, measurements and inspections. In doing so, it is necessary to ensure that all control activities are economical. Quality management systems are developed according to international standards ISO 9000 through 9004 . In case the construction company wants to certify its system, the procedure according to these standards must be strictly adhered to. The set of ISO 9000 international standards sets out the system requirements for product and production quality control (construction). It is a guide to how to create, or eventually reconstruct, the system in a particular case of construction, building product or implementation technology [7]. The system emphasizes adherence to established 
technological procedures and elaboration of building details. Testing, measurement and inspection activities are documented only. The quality management system is binding on all company employees. Infringements or improvisational deviations, which generally lead to a decrease in the quality of a building, are not admissible and may be grounds for dismissal.

\subsection{Knowledge management}

"Value is now being created through productivity and innovation.

Key specialists will be qualified specialists."

Peter F. Drucker

Knowledge management is about extracting and storing data and information through software, and developing and transferring knowledge and skills between workers. Knowledge Management is about increasing the organization's knowledge. It combines the extraction of data, information from systems (from enterprise applications, the Internet, etc.) with the development of people's knowledge (through education, increasing practical experience, transferring knowledge and skills among workers, etc.). However, it also includes the sharing of experience at meetings. It is a collective expression for "knowing more and still learning". Knowledge management is on the brink of human development and information management:

- Knowledge management is part of the development of people, human resources and the development of their knowledge (emphasis on tacit knowledge).

- Knowledge management is also part of information and information management and data governance, as data retention and extraction is an important part of knowledge management (emphasis on explicit knowledge).

Knowledge is tied to a particular person who acquires them through learning. Knowledge management is practically related in particular to preservation (using ICT) and the transfer of knowledge and skills among workers. The ability to create, transfer and apply knowledge becomes a key competitive advantage - in other words, today's economy is called the Knowledge Economy [8].

Similar approaches are also visible in the field of quality, which emphasizes innovation and continuous improvement of work and other practices (such as TQM or Six Sigma), which is nothing more than just using and managing knowledge in a specific area.

Karl Erik Sveiby defines knowledge management as an area synthesizing adequate elements at the border of human resources management and information management. [9]. It integrates knowledge, process orientation and IT knowledge and connects social and technical systems into one environment.

\section{Conclusion}

The holistic project is an idea where we do not consider the construction work only from the point of view of its need, use and technical solution, but we are dealing with the building work throughout its useful life in all its aspects. It is necessary to break away from purely technical or economic solutions and to perceive the construction work as part of social processes. It means that you have to ask questions not only from the point of view of marketing (what to build) or management (how to build it), but be aware of the answer to the question: "Why should I build a building?" So we ask for the meaning of the building work and from it we derive its location, scope, technical solution, minimization of environmental impact, costs of construction, maintenance and disposal. In this way, we are 
working on partial solutions. This is how buildings were considered in the past, and so we have preserved so many ancient, medieval and modern monuments, because their construction was broader in the social context and connected to thought streams, religious needs or social necessity (ancient aqueducts, etc.).

The current time, together with the increase in labor productivity, has accelerated and facilitated the construction, not only creating the richness available to all, but also pushing from the point of view of the importance of buildings. Quickly build and quickly cut. We are not concerned with the creation of cultural landscapes (on the contrary, pressure groups are pushing us back into the forest), urbanism is limited to Corbusier's settlements without people (or people devastating public space), and minimalism does not lead to beauty but simplicity. Today's time fulfills only the superficial social need to meet the general needs of everyone. Such a doctrine, however, leads to waste and the aim of this study was to point out the need to eliminate errors in the design and construction of buildings. It is also a mistake to build only to satisfy elementary needs (seemingly rational and justified by feasibility studies and use analyzes), without considering the context and the meaning of the action.

\section{References}

1. M. Holický, Development of Concepts of Reliability Assessment of Building Structures, National Conference RELIABILITY OF STRUCTURES (House of Technology Ostrava, 2000)

2. J. Solař, Faults and reconstruction of brick buildings, 12-13 (Grada Publishing Praha, 2011)

3. R.E. Melchers, Structural Reliability Analysis and Prediction, 437 (John Wiley \& Sons, Chichester, 1999)

4. M. Holický, M. Fuzzy, Probabilistic Optimisation of Building Performance. Automation in Construction, 437- 443 (1999)

5. P. Rothstein, Disaster Recovery Testing: Exercising Your Contingency Plan (FBCI, Editor Rothstein Associates, 2007)

6. I. Celbová, Introduction to Expert Systems Issues, Ikaros - Electronic Journal on Information Society, 8 (1999)

7. E. Hering, J. Trimel, H. Blank, Qualitätssicherung für Ingenieure (VDI-Verlag, 1993)

8. V. Bureš, Knowledge management and the process of its implementation: a guide for practice. (Grada Praha, 2007)

9. K. E. Sveiby, Managing \& Knowledge-based Assets, (Berrett-Koehler Publisher, Inc. San Francisko, 1997) 